\title{
Balloon valvuloplasty and angioplasty in congenital heart disease
}

\author{
GRAHAM A H MILLER \\ From the Brompton Hospital, London
}

SUMMARY Balloon dilatation valvuloplasty was performed in 16 patients with pulmonary valve stenosis aged 10 days to 17 years. Gradients were reduced in all but two patients and were $\leqslant 20$ $\mathrm{mm} \mathrm{Hg}$ after the procedure in all but these two and one other. Unsatisfactory initial results in these three patients were attributed to the use of too small a balloon in one patient (gradient subsequently abolished at repeat valvuloplasty), to a dysplastic valve in a neonate, and to the fact that there had been a previous surgical valvotomy with scar tissue formation in one patient. The good result was retained in six of seven patients followed up at three to six months. In one the gradient, having been reduced from 60 to $18 \mathrm{~mm} \mathrm{Hg}$, had risen to $35 \mathrm{~mm} \mathrm{Hg}$. Repeat valvuloplasty was technically impossible in this patient, but in two others residual gradients of 24 and $22 \mathrm{~mm}$ $\mathrm{Hg}$ were reduced to 4 and $8 \mathrm{~mm} \mathrm{Hg}$ respectively by repeat valvuloplasty. Balloon dilatation angioplasty was successful in dilating a severe stenosis at the lower limb of an atrial baffle (previous correction of complete transposition) and in dilating supravalvar stenosis of the pulmonary artery resulting from previous banding and debanding.

Thus balloon pulmonary valvuloplasty, though still a new technique, appears to be the treatment of choice in patients with typical pulmonary stenosis and thin mobile valves. Patients with dysplastic valves may be less suitable candidates for the procedure. Balloon angioplasty is likely to have other applications, including the treatment of postoperative stenotic lesions.

In $1982 \mathrm{Kan}$ and coworkers reported the first use of percutaneous balloon valvuloplasty for the successful treatment of a patient with pulmonary stenosis. ${ }^{1}$ Since that time the same group has reported details of 20 patients treated in this way with follow up data at two to 12 months in nine, ${ }^{2}$ and Lababidi and Wu have reported equally promising results with the procedure in another 18 patients. ${ }^{3}$ This report describes a personal experience of 16 patients with pulmonary valve stenosis treated by percutaneous balloon valvuloplasty. Data from repeat catheterisation three to six months after the procedure are available in seven of the patients.

Percutaneous balloon angioplasty has been used for the treatment of other congenital cardiac malformations including aortic coarctation and hypoplasia of pulmonary arteries. ${ }^{45} \mathrm{I}$ have used balloon angioplasty for the successful treatment of two post-

Requests for reprints to Dr GAH Miller, Cardiac Department, Brompton Hospital, Fulham Road, London SW3 6HP.

Accepted for publication 29 May 1985 operative complications: stenosis of the lower limb of an atrial baffle in a patient with previous correction of complete transposition and residual supravalvar pulmonary stenosis after debanding. Details of these two patients are also reported as these appear to be promising new applications of the technique.

\section{Patients and methods}

\section{TECHNIQUE}

The technique of balloon valvuloplasty has been described. ${ }^{1-3}$ The technique involves several steps. Firstly, percutaneous cannulation of a femoral vein (preferably the right) is performed. An end hole catheter (for example, Goodale-Lubin) is then passed into a pulmonary artery (preferably the left) and a guidewire advanced through this catheter until its tip is well out into the lung field. The catheter is then withdrawn while the position of the guidewire in the pulmonary artery is maintained. The balloon catheter is then advanced over the guidewire until the pulmonary valve is midway between the radio- 
opaque markers, which indicate the proximal and distal limits of the balloon. The balloon is then inflated with dilute contrast medium under pressure for approximately 20 seconds causing the pulmonary valve to rupture. The balloon is then deflated using negative pressure. This inflation is usually repeated once or twice during which time any air still in the balloon is aspirated into the inflating syringe.

The technique is simple and balloon valvuloplasty with preoperative and postoperative angiocardiograms and pressure measurements can be completed in 20-30 minutes. It may be useful, however, to describe the solutions to some of the problems that may be encountered. Firstly, an $18 \mathrm{~mm}$ balloon catheter (Medi-tech) (Medi-Tech Inc, Watertown, Mass 02171, USA) requires a No 10 French gauge (split) introducing sheath (Vygon, BP 7-95440, Ecoven, France); in practice I have found that it is often possible to advance these catheters directly through the skin incision without using an introducing sheath. Previous use of a No 9 French gauge vessel dilator will facilitate this. The initial skin incision must be of adequate size $-5 \mathrm{~mm}$ or so. An assistant presses on the skin incision at the stage when the end hole catheter (together with any introducing sheath that was used) has been withdrawn and the balloon catheter is being threaded over the guidewire since there will be bleeding at this time. Secondly, it is important that the balloon be centred on the pulmonary valve. If the balloon is too proximal or too distal it may advance (or retract) itself during inflation without rupturing the valve. It is remarkable how much of this large balloon can be accommodated in the pulmonary arteries distal to the valve. As viewed with anteroposterior screening it may be difficult to appreciate that the balloon is wrongly positioned, and for this reason the practice in this hospital is to perform biplane angiography before balloon valvuloplasty. The position of the valve is marked on the lateral video monitor, and, provided that the patient's position is not changed, the balloon is correctly positioned using lateral screening as an aid (Fig. 1). It is important to use a balloon whose inflated diameter is slightly larger than the diameter of the valve ring. The diameter of the valve ring is measured from lateral angiocardiograms using the known diameter of the angiographic catheter to obtain the magnification factor. Where a previous angiographic study has been performed this measurement is used to select the appropriate balloon size. In patients between the ages of 1 and 7 years, however, I have found the valve ring to be between 12 and $16 \mathrm{~mm}$ in diameter; the $18 \mathrm{~mm}$ balloon has been effective in all patients and is therefore used routinely in those over the age of 1 year without previous measurement of the angiograms.

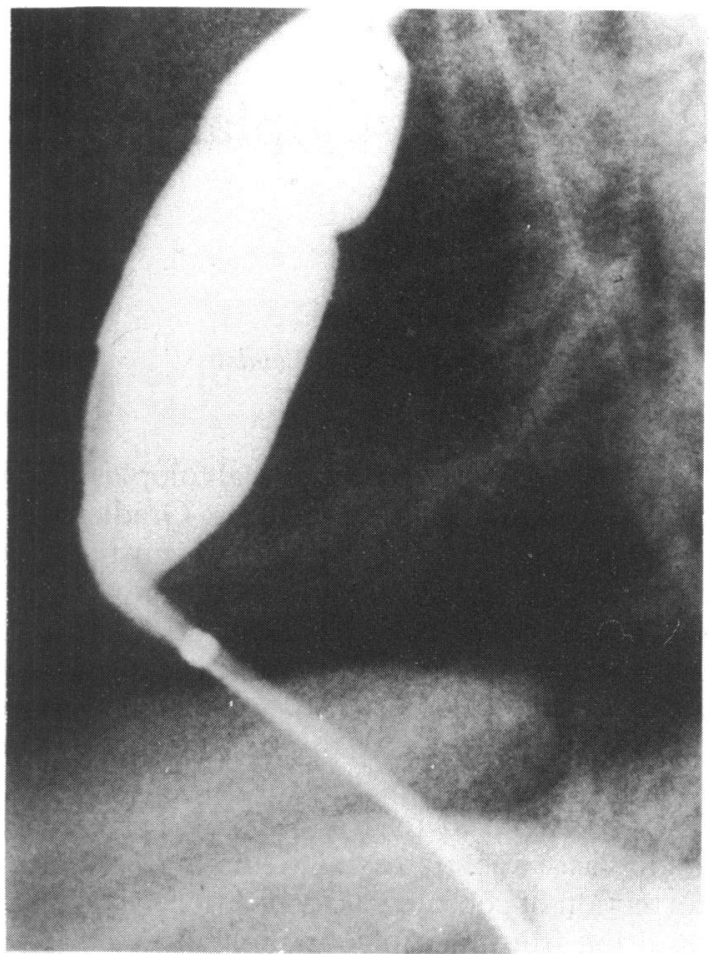

Fig. 1 Lateral angiogram showing the inflated angioplasty balloon positioned across the pulmonary valve. The valve is causing an indentation in the balloon, which disappears when the valve ruptures.

\section{Results}

PULMONARY VALVE STENOSIS

Balloon valvuloplasty was performed in 16 patients aged between 10 days and 17 years (Table). Preoperatively, right ventricular systolic pressure ranged between 37 and $87 \mathrm{~mm} \mathrm{Hg}$ (mean (SD) $64(15) \mathrm{mm} \mathrm{Hg}$ ) and pulmonary valve gradients between 19 and $71 \mathrm{~mm} \mathrm{Hg}$ (mean 43(14) $\mathrm{mm} \mathrm{Hg}$ ). After valvuloplasty a satisfactory result (mean gradient after valvuloplasty $18 \mathrm{~mm} \mathrm{Hg}$ ) was obtained in all but three patients (cases 2,4 , and 5 ). With the exception of these three, gradients were reduced to $\leqslant 20 \mathrm{~mm} \mathrm{Hg}$ (Fig. 2). Seven patients were recatheterised between three and six months after valvuloplasty; the good result was maintained in all but one (case 6), whose valve gradient had risen to 35 $\mathrm{mm} \mathrm{Hg}$ (having originally been reduced from 60 to $18 \mathrm{~mm} \mathrm{Hg}$ ). Attempted repeat valvuloplasty in this 6 month old infant was frustrated by failure to advance an $18 \mathrm{~mm}$ balloon into the pulmonary artery. Repeat valvuloplasty was successfully performed in two other patients (cases 4 and 9) reducing 
Table Angiographic data before (A) and after (B) balloon valvuloplasty, at follow up (C), and after repeat valvuloplasty (D) in patients with pulmonary valve stenosis

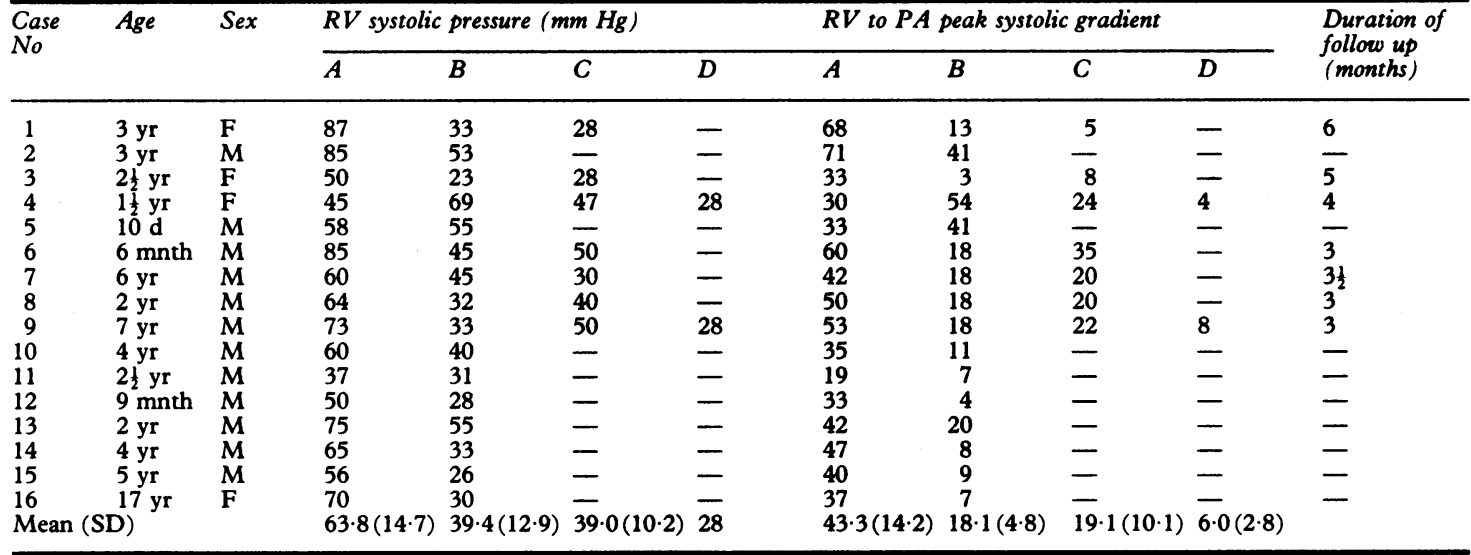

$\mathrm{RV}$, right ventricular; PA, pulmonary arterial.

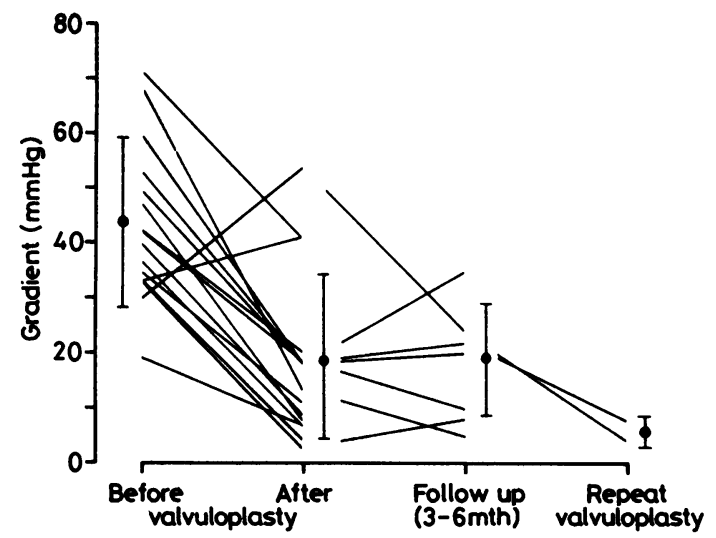

Fig. 2 Transverse gradients before and after balloon valvuloplasty and at follow up (3-6 months) in patients with pulmonary valve stenosis. The final gradients after repeat valvuloplasty at follow up in two patients are also shown. Bars denote mean (SD).

residual gradients of 24 and $22 \mathrm{~mm} \mathrm{Hg}$ to 4 and $8 \mathrm{~mm}$ $\mathrm{Hg}$ respectively.

The first of the three patients with an unsatisfactory initial result was the youngest patient (case 5) in our series, who presented at 10 days of age with critical pulmonary valve stenosis and a dysplastic valve. After valvuloplasty the valve gradient rose from 33 to $41 \mathrm{~mm} \mathrm{Hg}$. Surgical valvotomy was then performed when it was found that, although the valve had been split, an intimal tear in the pulmonary artery had resulted in haematoma formation and therefore continuing (supravalve) pulmonary stenosis. The second patient (case 2) in whom valvuloplasty was less than totally successful was aged 3 years and had had a previous surgical valvotomy for critical pulmonary stenosis as a neonate. The gradient was reduced from 71 to $41 \mathrm{~mm}$ Hg. Finally, in the third patient (case 4) the gradient actually rose from 30 to $54 \mathrm{~mm} \mathrm{Hg}$. In this patient the diameter of the valve ring was $15 \mathrm{~mm}$; $10 \mathrm{~mm}$ balloon was used at the initial valvuloplasty. Four months later the gradient was found to be $24 \mathrm{~mm} \mathrm{Hg}$ and a second valvuloplasty was performed using an $18 \mathrm{~mm}$ balloon. The gradient was therby reduced to $4 \mathrm{~mm} \mathrm{Hg}$.

\section{RELIEF OF BAFFLE STENOSIS}

Surgical correction of complete transposition (Mustard's operation) had been performed in one patient at the age of 11 months using a baffle of bovine pericardium. Signs of inferior caval obstruction lead to recatheterisation at the age of $2 \frac{1}{2}$ years. There was severe stenosis at the lower limb of the baffle and most of the lower body venous return was via the azygos system to the superior vena cava. Mean pressure in the inferior vena cava was $16 \mathrm{~mm} \mathrm{Hg}$ and there was a mean gradient of $11 \mathrm{~mm} \mathrm{Hg}$ between it and the systemic venous (left) atrium. Progressive dilatation of the stenosis was achieved using a $10 \mathrm{~mm}$ and then an $18 \mathrm{~mm}$ balloon. After the procedure the mean gradient had been reduced to $4 \mathrm{~mm} \mathrm{Hg}$ and there was considerable angiographic improvement (Fig. 3).

RELIEF OF SUPRAVALVAR PULMONARY STENOSIS One child had had a persistent ductus closed and had had pulmonary artery banding for ventricular septal defect in infancy. At 3 years of age the defect had 
Fig. 3 Case 17: angiograms showing severe stenosis at the lower limb of an atrial baffle (Mustard's operation) before (a) and after $(b)$ balloon angioplasty.

been closed and the pulmonary artery debanded. He presented to our hospital at the age of 6 years with signs and echocardiographic findings suggesting significant residual stenosis at the site of the band. Catheterisation showed a gradient of $23 \mathrm{~mm} \mathrm{Hg}$ between proximal and distal main pulmonary artery. Balloon angioplasty (18 $\mathrm{mm}$ balloon) reduced the gradient to $3 \mathrm{~mm} \mathrm{Hg}$ with improved angiographic appearances.

\section{Discussion}

That excellent relief of typical pulmonary valve stenosis can be achieved by balloon valvuloplasty is now well established..$^{1-3}$ It has yet to be established which, if any, patients are unsuitable candidates, and we do not yet know what will be the long term results obtained by this attractive technique. The patients reported here all had mild or moderate pulmonary stenosis; all had gradients of $<100 \mathrm{~mm} \mathrm{Hg}$. Six of the patients, however, reported by Lababidi and $\mathrm{Wu}^{3}$ and two of those reported by Kan $e t \mathrm{al}^{2}$ had gradients $>100 \mathrm{~mm} \mathrm{Hg}$ and still had a significant reduction in the gradient - though some had residual gradients of 35 to $82 \mathrm{~mm} \mathrm{Hg}$. Thus it would seem well worth attempting balloon valvuloplasty even in severe pulmonary stenosis, though a completely satisfactory result may not always be obtained. Of the three patients reported here who had an unsatisfactory result, one was due to the use of too small a balloon; the gradient was effectively abolished at a second study when a balloon of diameter slightly larger than that of the valve ring was used. Of the other two, one had had a previous surgical valvotomy and one was a neonate with a dsyplastic valve. Kan et al report one patient with a dysplastic valve in whom the benefit of (repeated) valvuloplasty was not maintained, ${ }^{2}$ and it may therefore be that patients with dysplastic valves or valves rendered dysplastic by previous surgery and scar tissue will be found to be less suitable for valvuloplasty than those with typical pulmonary stenosis and thin mobile "doming" valves. That balloon valvuloplasty can be successfully applied to neonates with critical pulmonary stenosis has been reported by Tynan et al, ${ }^{6}$ while at the other end of the age spectrum it has been successful in relieving pulmonary valve stenosis in a patient aged $59^{7}$ and was successful in a 17 year old 
patient here. The procedure appears to be ideal treatment for patients with only moderate pulmonary stenosis in whom the disadvantages of surgery, cosmetic and otherwise, may outweigh the advantages. This would not be the case, however, if the procedure is shown to have an appreciable complication rate. In the present series the only complication occurred in the neonate with a dysplastic valve. The femoral vein was patent and easily cannulated in all of the patients who were recatheterised one to six months later. Neither Lababidi and $\mathrm{Wu}^{3}$ nor Kan $e a^{2}$ reported any complications other than the inevitable bradycardia and hypotension that occurs while the balloon is inflated. Nor did these authors detect the appearance of an early diastolic murmur in any of their patients either immediately or at follow up; this has been my own experience. What is observed is a decrease in the intensity of the systolic murmur.

Although the short term (2-12 months) follow up results reported here by Kan $e t a l^{2}$ show that the good result is maintained, the long term results remain speculative. Kan et al draw an analogy with the good long term results of the Brock procedure and speculate that similar results will be obtained by balloon valvuloplasty. ${ }^{2}$ In this regard it is of interest to know whether valvuloplasty results in the splitting of valve tissue or merely (perhaps temporary) dilatation of the valve ring. I have experience of one patient in whom balloon valvuloplasty was performed during elective open heart surgery. Balloon inflation caused splitting of a commissure in this instance, and Lababidi and Wu reported an exactly similar experience in a single patient. ${ }^{3}$

Stretching of tissue is the likely mechanism for the success of balloon angioplasty in the present two postoperative cases. Here too it is not possible to know for how long the good result will be maintained, but even if palliation is only temporary the procedure would appear to be worth while since surgical correction in each instance would have been complicated by the presence of scar tissue. The procedure can, presumably, be repeated if necessary. It is of interest that balloon dilatation also appears to be successful in stretching scar tissue in another postoperative complication-coarctation "restenosis." 9

\section{References}

1 Kan JS, White RI Jr, Mitchell SE, Gardner TJ. Percutaneous balloon valvuloplasty: a new method for treating congenital pulmonary valve stenosis. $N$ Engl f Med 1982; 307: 540-2.

2 Kan JS, White RI Jr, Mitchell SE, Anderson JH, Gardner TJ. Percutaneous transluminal balloon valvuloplasty for pulmonary valve stenosis. Circulation 1984; 69: 554-60.

3 Lababidi Z, Wu JR. Percutaneous balloon pulmonary valvuloplasty. Am f Cardiol 1983; 52: 560-2.

4 Lock JE, Castaneda-Zuniga WR, Fuhrman BP, Bass JL. Balloon dilation angioplasty of hypoplastic and stenotic pulmonary arteries. Circulation 1983; 67: 962-7.

5 Singer MI, Rowen M, Dorsey TJ. Transluminal aortic balloon angioplasty for coarctation of the aorta in the new-born. Am Heart $\mathcal{F}$ 1982; 103: 131-2.

6 Tynan M, Jones O, Joseph MC, Deverall PB, Yates AK. Relief of pulmonary valve stenosis in first week of life by percutaneous balloon valvuloplasty [Letter]. Lancet 1984; i: 273.

7 Pepine CJ, Gessner IH, Feldman RL. Percutaneous balloon valvuloplasty for pulmonic valve stenosis in the adult. Am f Cardiol 1982; 50: 1442-5.

8 Kan JS, White RI Jr, Mitchell SE, Farmlett EJ, Donahoo JS, Gardner TJ. Treatment of restenosis of coarctation by percutaneous transluminal angioplasty. Circulation 1983; 68: 1087-94.

9 Lock JE, Bass JL, Amplatz K, Fuhrman BP, Castaneda-Zuniga $\mathrm{W}$. Balloon dilatation angioplasty of aortic coarctations in infants and children. Circulation 1983; 68: 109-16. 